\title{
Aplicação da membrana de látex natural e do extrato da pele de rã (Lithobates catesbiana) em feridas cirúrgicas cutâneas de ratos Wistar*
}

\author{
Application of natural latex membrane and extract of frog skin \\ (Lithobates catesbiana) (Shaw, 1802) in cutaneous surgical \\ wounds of Wistar rats
}

Flávia Neme Borsari, ${ }^{* *}$ Leonardo Martins Leal, ${ }^{* * *}$ Henrique Manoel Galves de Freitas, ${ }^{* *}$ Tais Harumi de Castro Sasahara, ${ }^{* * *}$ Marcia Rita Fernandes Machado*****

\begin{abstract}
Resumo
Implantou-se a membrana de látex natural e o extrato da pele de rã individualmente e em conjunto em feridas cutâneas de ratos com o intuito de se avaliar o processo de reparação tecidual e possíveis complicações. Utilizaram-se 60 ratos da linhagem Wistar divididos em grupos experimentais: grupo controle (GC), grupo membrana de látex (GM), grupo óleo do extrato da pele de rã (GO) e grupo membrana de látex e óleo de rã (GMO), cada um com 15 animais. Aos três, cinco, sete, 14 e 21 dias de pós-operatório, foi realizada eutanásia dos animais para avaliações macroscópicas e histológicas da região lesionada. Nas feridas dos animais do GM e do GC a cicatrização ocorreu mais cedo. No último tempo de avaliação, o sinal de lesão era mínimo; já no GMO, a cicatrização não foi completa e no GO a ferida teve o pior resultado, com presença de crosta no $21^{\circ}$ dia. Foram observadas, à microscopia de luz, células normais envolvidas no processo de reparação tecidual e formação de neovasos em todos os grupos. Conclui-se que em todos os grupos não houve rejeição dos biomateriais testados. Todavia, o grupo GM proporcionou melhor cicatrização com menos efeitos adversos quando comparada aos demais grupos testados.
\end{abstract}

Palavras-chave: cicatrização, cirurgia reconstrutiva, membrana de látex, extrato de pele de rã.

\begin{abstract}
In this study, the membrane of the natural latex and extract of the skin frog, isolated and together, where implanted to replace a cutaneous in the mice, with purpose for evaluating the tissue repair process and possible complication. Sixty Wistar rats ere divided in four experimental groups: control group (GC), membrane of the latex group (GM), oil of the frog group (GO) and group membrane of latex with oil of the frog group (GMO), each one with 15 animals. The animals were euthanized at three, five, seven, 14 and 21 days post-operative, followed by macroscopic and microscopic evaluations of the area of the lesion. In the wounds of the GM and GC, healing occurred earlier, in the latter evaluation time the signal was minimal injury, in the GMO healing was not complete and the wound GO had the worst outcome with presence of crust on the 21st day. There were observed by microscopic, normal cells involved in the tissue repair process and neovascularization in all groups. We conclude that in all groups there was no rejection of the biomaterials tested, however the GM group gave better healing with fewer adverse effects when compared to the other groups tested.
\end{abstract}

Keywords: healing, reconstructive surgery, latex membrane, extract of frog skin.

\section{Introdução}

As feridas de pele possuem grande importância clínica em função de sua alta frequência, da morbidade que causam, da alta incidência de proliferação bacteriana que ocorre na maioria delas e devido ao alto custo dos tratamentos, tanto em decorrência do preço dos medicamentos quanto da quantidade de fármacos utilizada, e ainda pelo tempo necessário para que ocorra cicatrização por segunda intenção (Sousa, 2007).

Vários materiais biológicos têm sido empregados como curativo oclusivo por possuírem propriedades antibacterianas e analgésicas, além de acelerar a formação de tecido de granulação e epitelização (Prevel et al., 1995). Os tecidos de origem biológica obtidos a partir de animais da mesma espécie ou de espécies diferentes comportam-se do ponto de vista imunológico, respectivamente, como materiais alogênicos e xenogênicos, podendo induzir rejeição, fator que restringe a eficácia e o tempo de uso como curativo ou enxerto (Chem et al., 1992; Jia et al., 1995; Schorlemmer; Kurrle, 1998).

Testes de biocompatibilidade e resistência "in vitro" e "in vivo" com o látex extraído da seringueira (Hevea brasiliensis) vêm sendo realizados nos últimos anos em diferentes espécies, incluindo

\footnotetext{
${ }^{*}$ Recebido em 13 de junho de 2014 e aceito em 30 de setembro de 2014.

** Médico-veterinário.

***Doutorando em Cirurgia Veterinária, FCAV, Unesp, Jaboticabal-SP, Brasil. Autor para correspondência: leonardo.vet@hotmail.com

****Pós-doutorando, Departamento de Morfologia e Fisiologia Animal, FCAV, Unesp, Jaboticabal-SP, Brasil.

*****Professor, Departamento de Morfologia e Fisiologia Animal, FCAV, Unesp, Jaboticabal-SP, Brasil.
} 
o homem. Os autores relatam que quando adequadamente processado, a membrana de látex possui propriedades que facilitam a regeneração tecidual ou atuam como arcabouço para o processo cicatricial de diversos tecidos do corpo (Oliveira et al., 2003; Pinho et al., 2004; Paulo et al., 2005; Rabelo et al., 2005; Balabanian et al., 2006; Carvalho et al., 2007; Sousa et al., 2007; Zimmermann et al., 2007; Frade et al., 2012).

A rã, como a maioria das espécies de anfíbios, apresenta grande variedade de substâncias químicas no muco secretado pelas glândulas epidérmicas, as quais são estudadas pela indústria farmacêutica para a fabricação de antibióticos e outros medicamentos (Clark et al., 1994; Mor et al., 1994; Feio, 1997). A pele de rã da espécie Lithobates catesbian (Shaw, 1802) tem sido utilizada como tratamento alternativo em queimaduras de segundo grau. Outra aplicação é em cobertura temporária em área doadora de enxerto de pele e em ferida com tecido em fase de granulação (Candido, 2001).

Assim, objetivou-se comparar qualitativamente de forma macroscópica e histológica os efeitos da aplicação isolada e conjunta da membrana de látex e do óleo do extrato da pele de rã (Rana catesbeiana), em lesões cutâneas provocadas experimentalmente na região dorsal de ratos Wistar.

\section{Material e métodos}

O projeto de pesquisa foi aprovado pela Comissão de Ética e Bem-Estar Animal (CEBEA) da FCAV, Campus de Jaboticabal, UNESP, sob protocolo $n^{\circ} 008579-0$, pois está de acordo com os Princípios Éticos na Experimentação Animal, adotado pelo Colégio Brasileiro de Experimentação Animal (COBEA).

Foram utilizados 60 ratos, machos, da linhagem Wistar pesando entre 150 e 200 gramas, provenientes do Biotério Central do Campus de Botucatu - UNESP. Os animais foram mantidos, durante a fase experimental, em gaiolas individuais de $30 \mathrm{~cm}$ x $20 \mathrm{~cm}$ x $18 \mathrm{~cm}$ localizadas no Biotério do Departamento de Morfologia e Fisiologia Animal, da FCAV, Campus de Jaboticabal, UNESP e receberam ração e água à vontade.

Os animais foram divididos aleatoriamente por tabela randomizada, em quatro grupos experimentais com 15 animais cada: Grupo Controle (GC); Grupo Membrana de Látex (GM); Grupo Óleo de Extrato da Pele de Rã (GO) e Grupo Membrana de Látex e Óleo de Extrato da Pele de Rã (GMO).

A membrana de látex natural utilizada foi a Biocure ${ }^{\circledR} .{ }^{1} \mathrm{O}$ produto foi mantido em sua embalagem original, em local fresco e seco, até o momento do procedimento cirúrgico.

Para a realização da ferida cirúrgica no dorso dos animais, após jejum alimentar de 12 horas, procedeu-se a anestesia geral com a associação anestésica de $1 \mathrm{ml}$ de quetamina $5 \% \mathrm{com} 1 \mathrm{ml}$ de xilazina $2 \%$, na dose de $0,2 \mathrm{ml} / 100 \mathrm{~g}$ de peso corporal pela via intramuscular. Os animais foram posicionados em decúbito ventral, realizou-se a tricotomia da região dorsal, antissepsia com iodo degermante $2 \%$, álcool $70 \%$ e iodo povidona $2 \%$. Em sequência, foi retirado um segmento de pele de aproximadamente $2 \times 2 \mathrm{~cm}$ da região torácica dorsal desses animais.

No GM, o segmento cutâneo excisado foi substituído por fragmento de membrana de látex (Pelenova Biotecnologia
S.A., São Paulo-SP) da mesma dimensão, suturada a pele com fio inabsorvível sintético (náilon 4-0) com pontos simples interrompidos em seus vértices. No GO, após a retirada de segmento cutâneo, aplicaram-se no local da lesão três gotas do óleo de extrato da pele de rã (Asmarana Indústria e Comércio de Produtos Naturais Ltda., Natal-RN). No GMO, instilaram-se no local da lesão três gotas do óleo de rã ${ }^{2}$ e em seguida inseriu-se a membrana como no GM, com náilon 4-0. No GC foi efetuada somente a excisão do segmento cutâneo na região dorsal dos ratos. Os animais, de todos os grupos, não receberam nenhuma medicação pós-operatória.

Para serem efetuadas avaliações macroscópicas e histológicas, foi realizada eutanásia de três ratos de cada grupo, aos três, cinco, sete, 14 e 21 dias do pós-operatório. Para isso, os animais receberam $400 \mathrm{mg} / \mathrm{kg}$ de tiopental sódico, por via intraperitoneal (IP). Após a eutanásia dos animais, procurou-se identificar a ocorrência de hemorragia e de rejeição, além da presença de crostas, secreção e necrose nos diferentes grupos.

Após os procedimentos descritos, um fragmento de $3 \times 3 \mathrm{~cm}$ foi coletado da região dorsal com $2 \times 2 \mathrm{~cm}$ referente à ferida cirúrgica mais $1 \mathrm{~cm}$ de margem com a interface pele/membrana ou pele/ processo cicatricial e fixado em Karnowisk.

Parte do material foi processado para inclusão em Histosec ${ }^{\circledR}$ (parafina - Merck, Darmstadt, Alemanha). A microtomia dos fragmentos foi realizada em micrótomo automático (Leica, RM 2155), com auxílio de navalhas descartáveis, obtendo-se cortes de $5 \mu \mathrm{m}$ de espessura, que foram fixados em lâminas e submetidos às colorações por Hematoxilina e Eosina (HE) e Tricrômio de Masson (TM). Outra parte desse material foi incluída em Historesin ${ }^{\circledR}$ (Merck, Darmstadt, Alemanha) (historesina) e seccionado em micrótomo automático (Leica-RM2155), utilizando-se navalhas de vidro, obtendo-se cortes de $3 \mu \mathrm{m}$ que foram corados com Hematoxilina e Floxina (HF) e Tricrômio de Masson (TM) (Behmer et al., 1976). Todas as preparações foram fotodocumentadas ao microscópio Leica DM 5000 B para análise morfológica.

Para cada período foram estudados, sob microscopia de luz, infiltrado inflamatório, constituído por eosinófilos, linfócitos, leucócitos, plasmócitos, monócitos, neutrófilos, macrófagos, mastócito; fibroblastos, fibrócitos, fibras colágenas e vasos sanguíneos.

\section{Resultados}

Não foram observados sinais macroscópicos de rejeição à membrana e ao óleo como presença de muco, ocorrência de hemorragia e sinais de necrose.

No terceiro dia pós-operatório, em todos os grupos, as lesões apresentavam-se hiperêmicas e não edematosas. No GC iniciouse a formação de crostas e tecido de granulação. Observou-se a presença de crosta com exsudato amarelado e tecido de granulação nas lesões referentes aos grupos GO e GMO. Neste último, em menor quantidade. No GM, a membrana estava aderida ao tecido muscular sem exsudação, sem granulação e sem crostas aparente (Figura 1). 


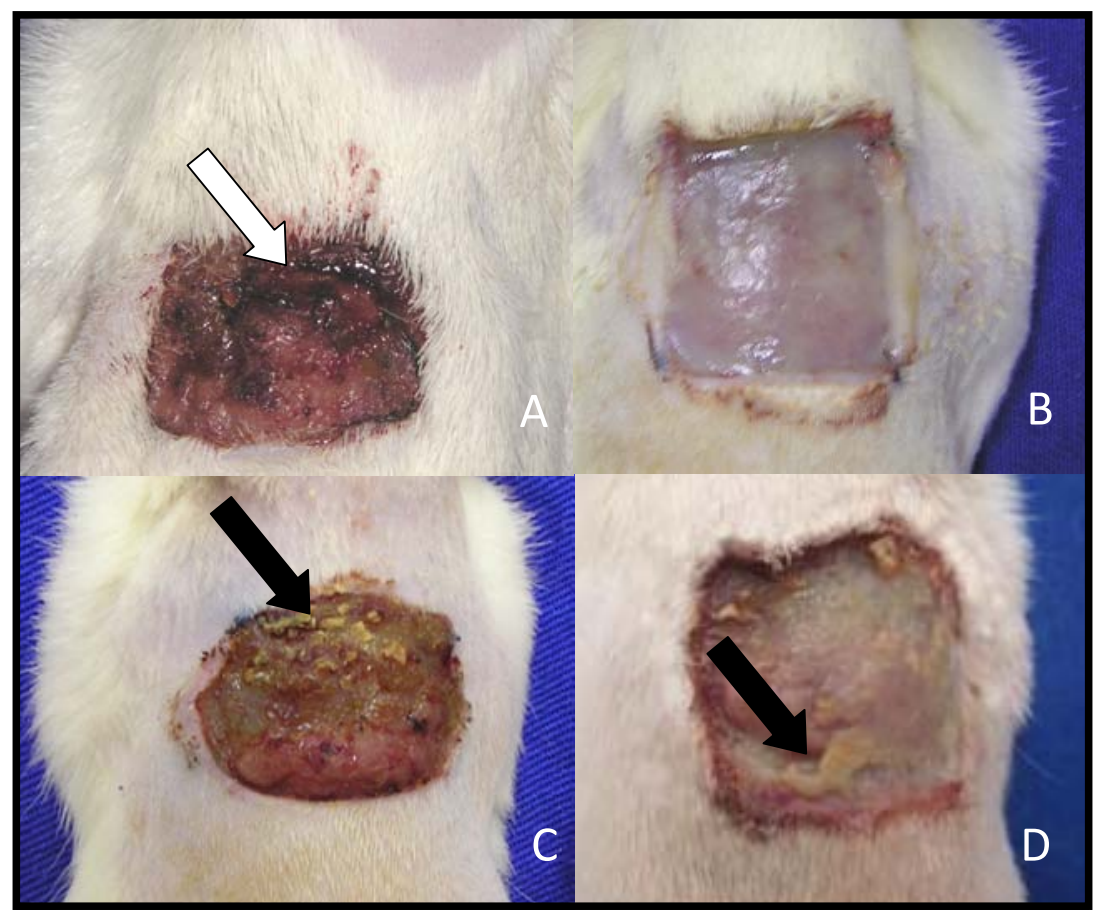

Figura 1: Fotografias das feridas cirúrgicas dorsais de ratos Wistar no terceiro dia pós-cirúrgico. A) GC B) GM C) GO e D) GMO. Observa-se hiperemia em todas as lesões, com presença de crostas em A (seta branca); presença de exsudato amarelado em C e D (setas pretas).

No quinto dia pós-operatório, as lesões de todos os grupos apresentaram-se com as margens retraídas. No GC, as crostas cobriram toda a lesão; no GM observou-se a presença de tecido de granulação nas margens da ferida; no GO verificou-se a presença de algumas crostas e aspecto hiperêmico com tecido de granulação. No GMO presenciou-se tecido de granulação por toda a ferida (Figura 2).

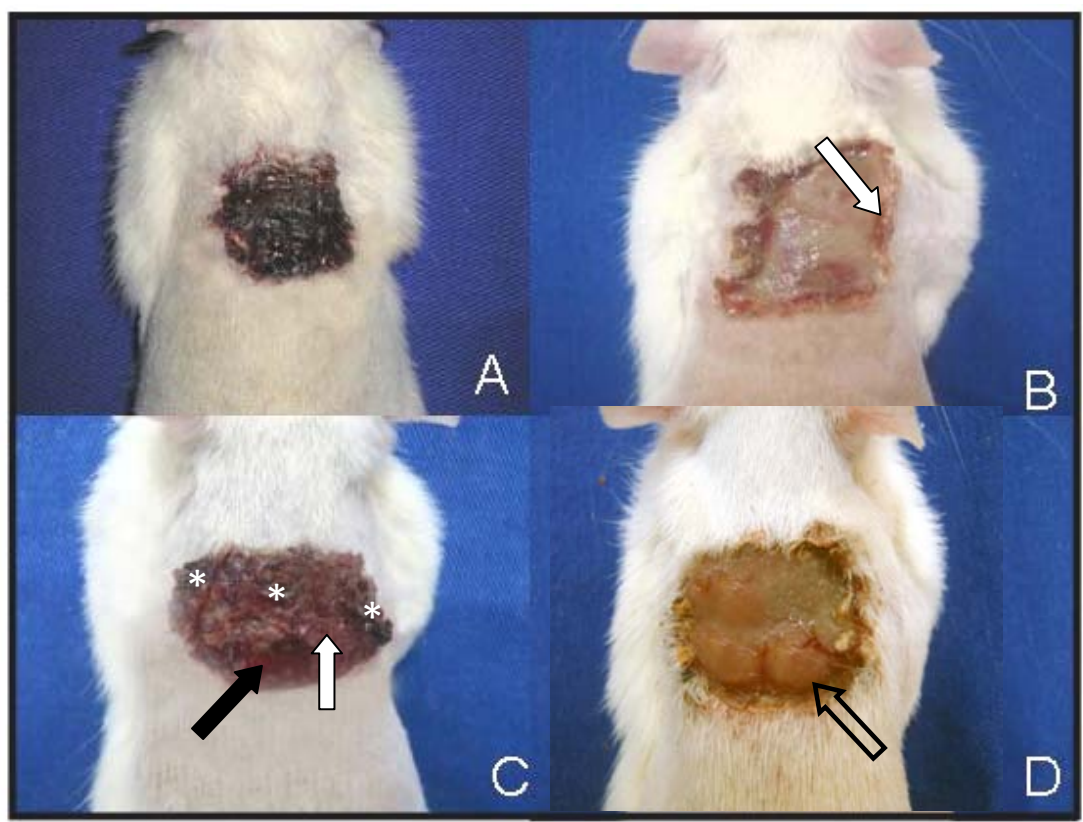

Figura 2: Fotografias de feridas cirúrgicas dorsais de ratos Wistar no quinto dia pós- cirúrgico A) GC B) GM C) GO e D) GMO. Verificam-se as margens das lesões retraídas, em todos os grupos; crostas que cobrem toda a lesão do GC; tecido de granulação nas margens da ferida do GM (seta branca); algumas crostas $\left(^{*}\right)$ e aspecto hiperêmico (seta branca) com tecido de granulação no GO (seta preta), o tecido de granulação intenso no GMO(seta vazada).
$\mathrm{Na}$ avaliação histológica das amostras à microscopia de luz, pôde-se observar no terceiro dia após o procedimento cirúrgico que todos os grupos apresentaram neovascularização e grande infiltrado inflamatório, formado especialmente por neutrófilos e linfócitos. Além dessas observações gerais, no GM e no GMO pôde-se observar a presença de algumas fibras colágenas; no GMO, macrófagos e monócitos foram visibilizados.

Aos cinco dias de pós-operatório, na avaliação histológica, os grupos ainda apresentavam células inflamatórias e neovasos; contudo, observou-se a presença de macrófagos e fibroblastos. Neste tempo de avaliação, no GM, a neovascularização era intensa.

Nas amostras colhidas aos sete dias após o procedimento cirúrgico, à microscopia de luz, ainda pôde-se observar em todos os grupos a presença de neovasos, células inflamatórias e fibras colágenas. No GM e no GMO observouse ainda a presença de adipócitos.

Após 14 dias do procedimento cirúrgico, na análise histológica, pôde-se observar nas amostras colhidas, assim como nos tempos iniciais, a presença de neovascularização e células inflamatórias. Entretanto, neste tempo de avaliação, observou-se a presença de fibras colágenas. Diferentemente dos demais grupos, o GMO apresentou epiderme em reorganização.

Por fim, na avaliação aos 21 dias de pósoperatório, observou-se que a epiderme estava cicatrizada nos grupos GM e GMO. No GC, a epiderme ainda estava em organização e no GO não havia sinais de reorganização epidérmica (Figura 3).

\section{Discussão}

Os tecidos de origem biológica, obtidos a partir de animais da mesma espécie ou de espécies diferentes, comportam-se, do ponto de vista imunológico, respectivamente, como materiais alogênicos e xenogênicos, podendo induzir rejeição, constituindo assim, fator que restringe a eficácia e o tempo de uso como curativo ou enxerto (Chem et al., 1992; Jia et al., 1995; Escudero et al., 1997; Schorlemmer; Kurrle, 1998). Entretanto, neste estudo não se verificou sinal marcante desse tipo de ocorrência frente aos tratamentos utilizados.

Quadros de hipersensibilidade ao látex são relatados na literatura em profissionais da saúde que constantemente manipulam objetos com essa matéria prima. (Montalvao et al., 2008). Todavia, nesta ocasião, assim como no estudo de Frade et al. (2012), na avaliação da hipersensibilidade em humanos que 


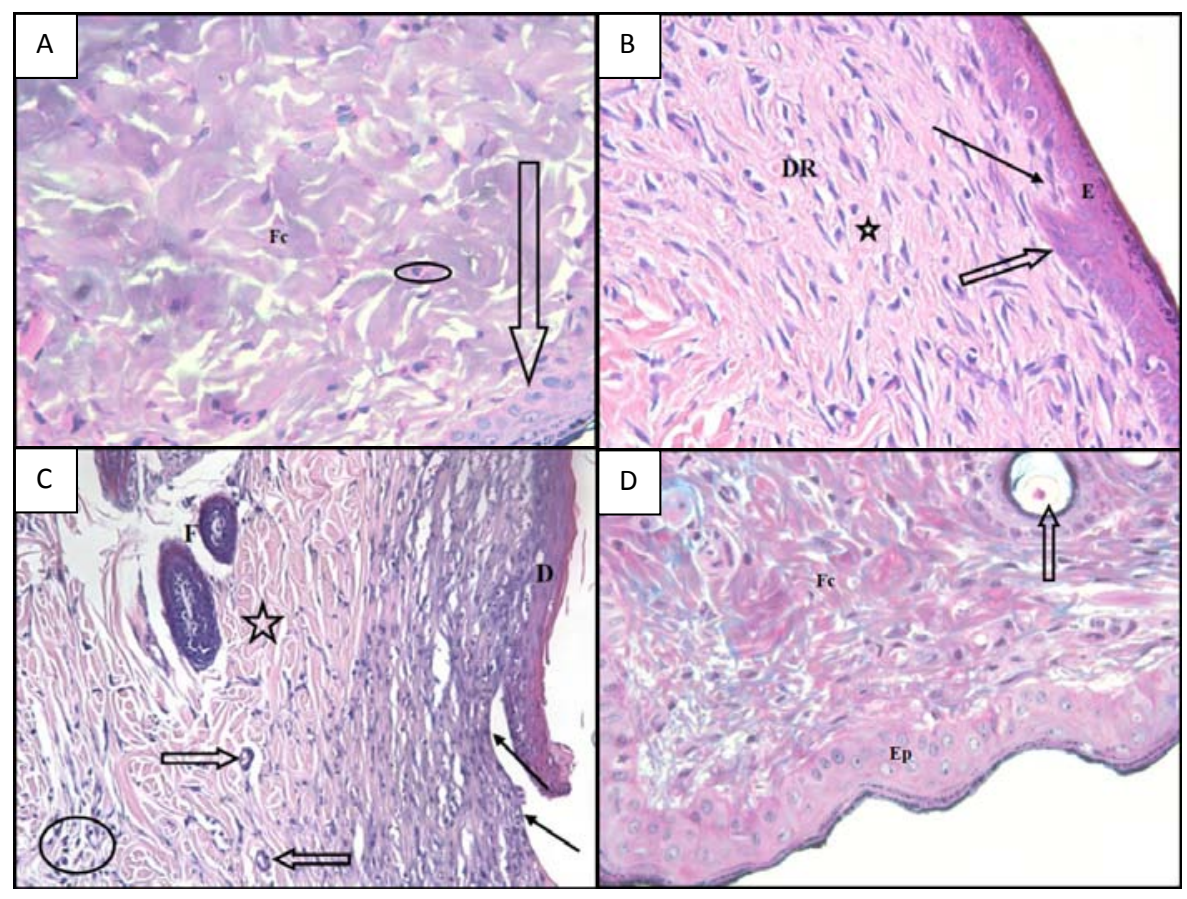

Figura 3: Fotomicrografias da lesão cutânea do dorso de rato ao $21^{\circ}$ dia após o procedimento cirúrgico. Em A, GC, nota-se epiderme em reorganização (seta) macrófago (círculo) e fibras colágenas (Fc) (Historesina, Hematoxilina Floxina, 40X). Em B, GM, observa-se epiderme cicatrizada (E), crista epidérmica (seta vasada), papila dérmica (seta cheia), derme reticular (DR), fibras colágenas (estrela) (Parafina, Hematoxilina Eosina, 40X). Em C, GO, nota-se ausência de regeneração epidérmica (seta cheia), derme (D) em cicatrização pela presença de fibras colágenas (estrela), núcleos de células do tecido conjuntivo (círculo), anexo cutâneo $(F)$, além de vasos (seta vazada) (Parafina, Hematoxilina Eosina, 20X). Em D, GMO, observa-se tecido epitelial em organização (Ep), fibras colágenas (Fc) e folículo piloso (seta) (Historesina, Tricrômio de Masson, 40X).

receberam curativo de biomembrana de látex, nenhum animal dos grupos membrana de látex (GM) e membrana de látex mais óleo de rã (GMO), apresentaram qualquer tipo de reação de hipersensibilidade e subsequente rejeição da membrana.

$\mathrm{Na}$ análise macroscópica, verificadas nos dias três, cinco, sete, 14 e 21 de pós-operatório, em todos os grupos, com exceção do grupo GM, a observação da presença de crosta formada por fibrinas e exsudato inicialmente, seguida por tecido de granulação, retração das bordas da ferida e por fim a epitelização corroboram com as observações feitas por Cotran et al. (2000) sobre o processo cicatricial normal da pele.

No GM, a não ocorrência de crostas e exsudação no período inicial está relacionada com a cobertura da ferida proporcionada pela membrana de látex que apresenta fatores de crescimento, tais como fator de crescimento vascular endotelial (VEGF) e fator de crescimento transformante 1 (TGF_1)" em sua composição, os quais, possivelmente, sejam responsáveis pela indução da cicatrização mais eficiente (Frade et al., 2004). Todavia, esta observação não pode ser extrapolada ao grupo GMO, pois, apesar desse grupo também receber a membrana, provavelmente o óleo de rã pode ter favorecido maior reação tecidual e consequente formação de crostas (Falcão et al., 2002).

Nos animais que receberam apenas o óleo de rã (GO), a presença de crosta ainda era evidente aos 21 dias de pós-operatório, fato que corrobora em partes com Falcão et al. (2002) ao investigarem o efeito da pele de rã (Rana catesbeiana) aplicadas como curativo oclusivo em feridas cutâneas de cães, que constataram grande reação tecidual do hospedeiro, levando a rejeição do implante nos animais que receberam esse biomaterial.

Apesar do atraso na cicatrização dos animais do GO e GMO, provavelmente pela grande formação crostosa com evidente exsudação presenciada, não houve rejeição do hospedeiro, da mesma forma que Gomes et al. (1995) também não a observaram ao utilizarem a pele de Rana catesbeiana como cobertura temporária de feridas produzidas por queimadura grave em humanos.

Ao se comparar, macroscopicamente, os eventos ocorridos entre os grupos estudados nesta oportunidade, é clara a constatação da regeneração tecidual, com melhor eficiência no GM, pois no $21^{\circ}$ dia de pós-operatório a cicatrização das lesões estava completa, assim como no GC. Ademais, o GM apresentou boa formação de tecido de granulação, sem exsudação e sem crostas aparentes nos períodos iniciais (Batista et al., 1996; Thomazini et al., 1997; Lachat et al., 1997; Potério-Filho, et al., 1999; Mente; Ceneviva, 2001; Mrué et al., 2004; Paulo et al., 2005; Sousa et al., 2007).

No grupo onde se utilizou apenas o óleo de rã, a reparação foi mais retardada quando comparada aos tratamentos anteriores, pois no período final de avaliação aos 21 dias de pós-operatório, a ferida estava em fase retardada de cicatriazação, com ocorrência de crostas. No caso do óleo de rã deve-se considerar as colocações de Falcão et al. (2002), que ressaltaram a necessidade do desenvolvimento de outros projetos com o propósito de estabelecer o modo mais eficaz de utilizar a pele de Rana catesbeiana, como curativo biológico oclusivo, em feridas cutâneas excisionais.

Ao se analisar as preparações microscópicas referentes aos grupos e dias de avaliação propostos neste experimento, constatou-se, de forma geral, a verificação de características bem semelhantes às relatadas por Cotran et al. (2000) com desenvolvimento de um processo de cicatrização por segunda intenção.

Mediante análise das amostras histológicas dos diferentes grupos estudados, constatou-se a ocorrência de evidente processo de neovascularização nas amostras do GM, provavelmente em decorrência da potente ação angiogênica desse produto, fato que levou à aceleração da cicatrização (Potério-Filho et al., 1999; Sader et al., 2000; Oliveira et al., 2003; Frade et al., 2004; Pinho et al., 2004; Friolani, 2008). 


\section{Conclusão}

Mediante os resultados obtidos, pode-se concluir que tanto a utilização da membrana de látex natural, quanto da combinação da membrana e do óleo de rã, como apenas do óleo de rã, foram biocompatíveis, uma vez que não induziram à reação imunológica de rejeição. Todavia, o grupo GM promoveu intensa neoangiogênese e reparação tecidual mais acelerada com mínima exsudação da ferida nos tempos iniciais, quando comparada aos outros grupos, o que a torna a melhor opção entre os grupos avaliados.

\section{Agradecimentos}

À Fundação de Amparo a Pesquisa do Estado de São Paulo (FAPESP), sinceros agradecimentos pelo financiamento do estudo em questão.

\section{Referências}

BALABANIAN, C.A.C.; COUTINHO-NETTO, J.; LAMANOCARVALHO, T.L.; LACERDA, S.A.; BRENTEGANI, L.G. Biocompatibility of natural latex implanted into dental alveolus of rats. Journal of Oral Science, v. 48, n. 4, p. 201-205, 2006.

BATISTA, L.C.; DALECK, C.R.; SHIMANO, A.C; ALESSI, A.C.; ABRAHÃO, M.S.

Estudo comparativo da resistência à tração do peritônio (bovino, equino, suíno e canino) a fresco e conservado em glicerina. Brazilian Journal of Veterinary Research and Animal Science, v. 33, p. 305-312, 1996.

BEHMER, A.O.; TOLOSA, E.M.C.; FREITAS-NETO, A.G. Manual de técnicas para histologia normal e patológica. São Paulo: Edart, 1976. $239 \mathrm{p}$.

CANDIDO, L.C. Nova abordagem no tratamento de feridas. São Paulo: Editora SENAC-SP, 2001. 282 p.

CARVALHO, B.R.; REIS, R.M.D.; COUTINHO NETTO, J.; MOURA, M.D.D.; NOGUEIRA, A.A.; FERRIANI, R.A. Natural latex (Hevea brasiliensis) mold for neovaginoplasty. Revista Brasileira de Ginecologia e Obstetrícia, v. 30, n. 1, p. -35, 2008.

CHEM, W.Y.J.; ROGERS, A.A.; LYDON, M.J. Characterization of biologic properties of wound fluid collected during early stages of wound healing. J. Invest. Dermatol., v. 99, p. 559-564, 1992.

CLARK, D.P.; DURELL, S.; MALOY, W.L.; ZASLOFF, M. Ranalexin, a novel an timicrobial peptide from bullfrog (Rana catesbeiana) skin, structurally related to the bacterial antibiotic, polymyxin. The Journal of Biological Chemstry, v. 269, n. 14, p. 10849-10855, 1994.

COTRAN, R.S.; KUMAR, V.; COLLINS, T. Patologia Estrutural e Funcional. 6. ed. Rio de Janeiro: Guanabara Koogan, 2000. 1251 p.

ESCUDERO, M.D.; OTERO, J.; GAGO, E.; El donante de tejidos. IN: NAVIDADE-LÓPEZ, A.; KULISEVSKY, J.; CABALLERO, F. (Eds.). El donante de órganos y tejidos: evaluación y manejo. Barcelona: Springer, 1997, p. 508-520.

FALCAO, S.C.; LOPES, S.L.; COELHO, A.R.B; ALMEIDA, E.L.D. Pele de Rana Catesbeiana como curativo biológico oclusivo no tratamento de feridas cutâneas produzidas em cães: Alterações macroscópicas e microscópicas resultantes da interação desses tecidos. Estudo preliminar. Acta Cir. Bras. v.17, n. 3, p. 151-159, 2002.

FEIO, R.N. Diversidade de anfíbios no Brasil. In: ENCONTRO NACIONAL DE RANICULTURA, INTERNATIONAL MEETING ON FROG RESEARCH AND TECHNOLOGY, 2., 1997. Anais... Santos, 1997, p. 67-74.
FRADE, M.A.C.; CUNHA, F.Q.; COUTINHO-NETTO, J.; FOSS, N.T. Úlcera de perna: caracterização clínica e perfil imunohistopatológico da cicatrização na presença de biomembrana de látex natural da seringueira Hevea brasiliensis. In: REUNION ANUAL DE DERMATOLOGUS LATINOAMERICANOS DEL CONO SUR, 23., 2004, Lima. Anais... Lima, 2004.

FRADE, M.A.C.; ASSIS, R.V.; COUTINHO NETTO, J.; ANDRADE, T.A.; FOSS, N.T. The vegetal biomembrane in the healing of chronic venous ulcers. Anais Brasileiros de Dermatologia, v. 87, n.1, p. 45-51, 2012.

FRIOLANI, M. Utilização da biomembrana de látex de seringueira (hevea brasiliensis) em lesões diafragmáticas de coelhos - estudo experimental. 2008. 62 f. Dissertação (Mestrado em Cirurgia Veterinária) - Faculdade de Ciências Agrárias e Veterinária, Universidade Estadual Paulista, Jaboticabal, SP, 2008.

GOMES, D.R.; SERRA, M.C.; PELLON, M.A. Queimaduras. Rio de Janeiro, 1995.

Reinventer, $305 \mathrm{p}$.

JIA, X.; ZHU, Z.; KONG, Q. Storage temperature and skin xenograft survival. Chung Hua Wai Ko Tsa Chih, v. 33, p. 184185, 1995.

LACHAT, J. J.; MRUE, F.; THOMAZINI, J. A.; ZABOROWSKI, A.C.; CENEVIVA, R.; COUTINHO-NETTO, J. Morphological and biochemical studies of biocompatibility of a membrane manufactured from the natural latex of Hevea brasiliensis. Acta Microscópica, v. 6, p. 758-759, 1997.

MENTE, E.D.; CENEVIVA,R. - Transplante de ilhotas pancreáticas em dispositivo de imunoisolamento celular. Acta Cir. Bras., São Paulo, v. suppl. 1, 2001.

MONTALVÃO, L.N.; PIRES, M.C.; DE MELLO, J.F.. Alergia ao látex em profissionais de saúde de São Paulo, Brasil Latex allergy in healthcare professionals in the State of Sao Paulo, Brazil. An Bras Dermatol, v. 83, n. 3, p. 213-220, 2008.

MOR, A.; KHALED, H.; NICOLAS, P. The vertebrate peptide antibiotics dermaseptins have overlapping structural features but target specific microorganisms. The Journal of Biological Chemistry, v. 269, n. 50, p. 31635-31641, 1994.

MRUÉ, F.; COUTINH-NETTO, J.; CENEVIVA, R.; LACHAT, J.J.; THOMAZINI, J.A.; TAMBELINI, H. Evaluation of the biocompatibility of a new biomembrane. Materials Research, v. 7, n. 2, p. 277-283, 2004.

OLIVEIRA, J.A.A.; HYPPOLITO, M.A.; COUTINHO-NETTO, J.; MRUÉ, F. Miringoplastia com a utilização de um novo material biossintético. Revista Brasileira de Otorrinolaringologia, v. 89, n. 5, p. 649-655, 2003. 
PAULO, N.M.; LIMA, F.G.L.; JÚNIOR, J.T.S.; FLEURY, L.F.F.; SANT'ANA, F.J.F.; BORGES, A.C.; TELLES, T.C. Membrana de látex da seringueira (Hevea brasiliensis), com e sem polilisina a $0,1 \%$ e tela de márlex na reconstrução de defeitos iatrogênicos da parede abdominal de ratos. Acta Cir. Bras., v. 20, n. 5, p. 305310, 2005.

PINHO, E.C.C.M.; SOUSA, S.J.F.; SCHAUD, F.; LACHAT, J.J.; COUTINHO-NETTO, J. Uso experimental da biomembrana de látex na reconstrução conjuntival. Arq Bras Oftalmol, v. 67, p. 27-32, 2004.

POTÉRIO-FILHO, J.; SILVEIRA, S.A.F.; POTÉRIO, G.M.B.; MRUÉ, F.; COUTINHO-NETTO, J. O uso do látex natural com polilisina $0,1 \%$ na cicatrização de úlceras isquêmicas. In: CONGRESSO BRASILEIRO DE ANGIOLOGIA E CIRURGIA VASCULAR, 33, 1999, BELO HORIZONTE. Anais... Belo Horizonte: Sociedade Brasileira de Angiologia e Cirurgia Vascular, 1999. p. 156.

PREVEL, C.D.; EPPLEY, B.L.; SUMMERLIN, D.J.; JACKSON, J.R.; MCCARTY, M.; BADYLAK, S.F. Small intestinal submucosa: utilization for repair of rodent abdominal wall defects. Annals of Plastic Surgeryv, v. 35, p. 374-380, 1995.

RABELO, E.R.; SANT'ANA, F.J.F.; PAULO, N.M.; ROMANI, A.F.; SILVA, L.A.F.; VIU, M.A.O. et al. Emprego do compósito látex, polimida e polilisina a $01 \%$ na correção cirúrgica de hérnias umbilicais recidivantes em bovinos leiteiros. Acta Scientiae, v. 33, n. 2, p.169-175, 2005.
SADER, S.L.; COUTINHO-NETTO, J.; BARBIERI NETO, J.; MAZZETTO, S.A.; ALVES JR, P.; VANNI, J.C.; SADER, A.A. Substituição parcial do pericárdio de cães por membrana de látex natural. Revista Brasileira de Cirurgia Cardiovascular, v. 15, n. 4, p. 338-344, 2000.

SCHORLEMMER, H.V.; KURRLE, R.S. Malononitrilamides reduce $\lg \mathrm{M}$ e $\lg \mathrm{G}$ xenoantibodies and prolong skin xenografts survival in a mouse-to-rat model. Transplant Proc, v. 30, p. 976979, 1998

SOUSA, L.C.A.; PIZA, M.R.T.; NETTO, J.C.; RUIZ, B.; SCHMIDT, V.B. Biomembrana de látex: novo método para o revestimento da cavidade aberta nas timpanomastoidectomia. Rev. Bras. Otorrinolaringol, v. 73, n. 3, 2007.

THOMAZINI, J.A.; MRUE, F.; LACHAT, J.J.; ZABOROWSKI, A. .; DURAN, J.H.R.; CENEVIVA, R.; COUTINHO-NETTO, J. Morphological and biochemical characterization of a prosthesis manufactured from natural latex of Hevea brasiliensis for medical utilization. Acta Microscópica, v. 6, p. 798-799, 1997.

ZIMMERMANN, M.; RAISER, A.G.; BARBOSA, A.L.T.; NOVOSAD, D.; STEFFEN, P.B.; STEFFEN, R.P.B.;

LUKARSEWSK, R.; SOARES, M.; LINDINGER, R.; JÚNIOR, F.P. Teste de biocompatibilidade e resistência de membranas de látex em cães. Ciência Rural, v. 37, n. 6, 2007. 